East African Medical Journal Vol. 77 No. 12 December 2000

PREDICTORS OF TOILET OWNERSHIP IN SOUTH AFRICA

J. M. Kirigia, MA, PhD, World Health Organisation, Regional Office for Africa and L. Kainyu, BEd, MEd, African Health Education and Economics Research Associates

Request for reprints to: Dr. J. M. Kirigia, PDC Unit, WHO, Regional Office for Africa, Ward C, Medical School, Parirenyatwa Hospital, P. O. Box BE 773, Harare, Zimbabwe.

\title{
PREDICTORS OF TOILET OWNERSHIP IN SOUTH AFRICA
}

\author{
J. M. KIRIGIA and L. KAINYU
}

\begin{abstract}
Background: To date no study in South Africa (to our knowledge) has attempted to isolate the key socio-economic variables associated with toilet ownership.

Objective: To contribute towards bridging knowledge-gap by identifying the key predictors of toilet ownership.

Design: Cross-sectional national household sample survey.

Setting: South African Health Inequalities Survey, 1994.

Subjects: Three thousand seven hundred and ninety six respondents aged between 16 and 64 years.

Interventions: Non-intervention qualitative response econometric study.

Main outcome measures: Respondent ownership of a toilet in their house (or compound).

Results: The study revealed that respondents' area of residence, health insurance coverage, income, age (in years), gender, level of education, health education, racial group, and employment status have statistically significant positive impact on the likelihood of toilet ownership.

Conclusion: Any government policies geared at improving living conditions (incomes, education, health education, and employment opportunities) for the less-well-to-do in urban and rural areas would increase the likelihood of toilet ownership in South Africa.
\end{abstract}

\section{INTRODUCTION}

Basic sanitation is one of the cornerstones of any public health programme in any civilised society. The dramatic reduction in death rates in developed countries long before the discovery of antibiotics or other effective medical interventions is attributed to improved nutrition, housing less vulnerable to vermin, cleaner drinking water, improved isolation from human faecal contamination (through use of latrines), and use of soap(1,2). It was essentially because of this evidence that the World Health Organisation decided to include basic sanitation as one of the elements of the primary health care strategy.

In 1977, the United Nations Conference held at Mar del Plata re-affirmed the goal that all people, whatever their stage of development and their socio-economic conditions have the right to have access to appropriate disposal of sewage. Yet, in 1990 the actual urban sanitation coverage in Africa, America, South East Asia, Eastern Mediterranean and Western Pacific was 68, 82, 50, 79 and $92 \%$ respectively. Thus, 47.24 million, 58 million, 175.88 million, 36.36 million, and 26.84 million urban people in the five regions had no access to sanitation facilities. The situation was even worse in rural areas of Africa, America, South East Asia, Eastern Mediterranean and Western Pacific, where sanitation coverage was 22, 36, 12, 20 and $76 \%$, respectively, implying that $264.72,79.28,839.73$, 174.22, and 244.59 millions of rural people in Africa,
America, South East Asia, Eastern Mediterranean and West Pacific had no access to sanitation facilities(3). By 1997, the situation was no different in South Africa where $34 \%$ of the marginal urban population and $54 \%$ of the rural population had no latrine facilities(4). In 1992, the World Bank estimated the positive health impact of providing those who now lack it with access to safe drinking water and adequate sanitation would be the annual prevention of two million deaths from diarrhoea in children under five; 200 million fewer cases of diarrhoeal illness, 300 million fewer infections with roundworms, 150 million fewer infections with schistosomes, and two million fewer infections with guinea worm(5).

The environmental health objective of the postapartheid South African government is to increase to $80 \%$ the population which has access to basic environmental health needs such as sanitation, water, shelter and safe food(4). Unfortunately, given the legion of competing demands on the scarce public health sector resources, the government's ability to increase coverage to $80 \%$ and eventually to $100 \%$ is quite limited. So there is need for community participation in both provision and maintenance of latrines. Unfortunately, no study (to our knowledge) in South Africa has attempted to isolate the key socioeconomic variables correlated with toilet ownership. The purpose of this study was to contribute towards bridging that knowledge-gap by identifying the key predictors of toilet ownership. 


\section{MATERIALS AND METHODS}

Data: Data from a national probability sample of 4,000 households formed the basis for our analysis. However, the analysis is based on 3796 respondents aged between 16 and 64 years. The data were collected by the Market Research Africa from October 1994 to February 1995 as part of the Kaiser Family Foundation CASE study of health inequalities in South Africa. City, suburbs, townships, farms, rural dwellings, and informal settlements were all included in the sample(6). The data-set contains various socio-economic characteristics (such as: marital status, educational attainment, age, race, household size, occupation), place of residence and knowledge of the main mode of HIV/AIDS transmission. In the survey, the respondents were asked whether they had a toilet in their house (or compound) and the type of toilet. Toilet ownership responses were re-coded into a dummy dependent variable taking a value of 1 if the respondent reported to own a toilet and 0 otherwise.

Conceptual framework: When faced with a dummy dependent variable, one has to estimate either a linear probability model (LPM), a binary probit model (BPM) or a binary logit model (BLM) specification. The LPM has several statistical problems(7). However, its binding weakness is that it does not constrain the estimated probabilities $\left(\mathrm{P}_{\mathrm{i}}\right)$ between the meaningful range of 0 and 1 . To avoid the unboundedness problem, we need to estimate either a BPM or a BLM specification with the maximum likelihood estimator (MLE) method(8). The former has a cumulative normal distribution and the latter a cumulative logistic distribution. Thus, the choice between the two models really hinges on the distribution function one prefers. Amemiya(8) discusses these qualitative response models and the MLE method. For comparative purposes we estimated the three qualitative response model specifications.

\section{(a) Linear Probability Model (LPM)}

Toilet $\phi_{1}=\beta_{0}+\beta_{1}$ Province $+\beta_{2}$ Area $+\beta_{3}$ Medaid $+\beta_{4}$ Income $+\beta_{5}$ Age $+\beta_{6}$ Sex $+\beta_{7}$ Education $+\beta_{8}$ Hsize $+\beta_{9}$ Knowledge $+\beta_{10}$ Race $+\beta_{11}$ Employment $+\beta_{12}$ Marital $+\varepsilon_{1} \ldots$ (1)

\section{(b) Binary Logit Model (BLM)}

$\operatorname{In}\left(\right.$ TOILET $_{\mathrm{i}} / 1-$ TOILET $\left._{\mathrm{i}}\right)=\beta_{0}+\beta_{1}$ Province $+\beta_{2}$ Area + $\beta_{3}$ Medaid $+\beta_{4}$ Income $+\beta_{5}$ Age $+\beta_{6}$ Sex $+\beta_{7}$ Education $+\beta_{8}$ Hsize $+\beta_{9}$ Knowledge $+\beta_{10}$ Race $+\beta_{11}$ Employment $+\beta_{12}$ Marital $+\varepsilon_{i} \quad \ldots$ (2)

where 'In' is the natural logarithm; 'TOILET $\mathrm{i} /$ /l-TOILET $\mathrm{i}$ ' is the odds ratio; ' $\beta_{0}$ ' is the intercept term (it shows the probability of toilet ownership if all the explanatory variables were equal to zero); the other ' $B \mathrm{~s}$ ' are explanatory variables coefficients measuring the impact of a one-unit change in each explanatory variable on the log of odds of toilet ownership, holding all the other variables constant; ' $\varepsilon$ ' is a random error term capturing data measurement errors and omitted variables; and the explanatory variables are defined in Table 1 . The expected value of Toilet $i_{i}$ continues to be $\mathrm{P}_{\mathbf{i}}$, the probability that the ith person will make the choice described by $D_{i}=1$ (i.e. $i^{\text {th }}$ person owns a toilet). Consequently, the dependent variable of the above equation can be thought of as the log of the odds that the choice in question will be made.

\section{(c) Binary Probit Model (BPM)}

$$
\mathrm{Pi}=1 / \sqrt{2 \pi} \int_{-\infty}^{\mathrm{zi}} \mathrm{e}^{-\mathrm{s}^{2 / 2}} \mathrm{ds} \quad \ldots
$$

where:

$\mathrm{P}_{\mathrm{i}}=$ the probability that the dummy TOILET $_{i}=1$

$\mathrm{Zi}=\beta_{0}+\beta_{1}$ Province $+\beta_{2}$ Area $+\beta_{3}$ Medaid $+\beta_{4}$ Income $+\beta_{5}$ Age $+\beta_{6}$ Sex $+\beta_{7}$ Education $+\beta_{8}$ Hsize $+\beta_{9}$ Knowledge $+\beta_{10}$ Race $+\beta_{11}$ Employment $+\beta_{12}$ Marital $+\varepsilon_{i}$

$\mathrm{s}=\mathrm{a}$ standard normal variable.

$\infty=$ infinity.

$\sqrt{ }=$ square root.

$\pi=3.143$

$\int=$ sigma sign

$\mathrm{e}=$ exponent $(=2.718)$.

Data analysis: The statistical analysis was conducted using the Intercooled Stata version of Stata for Windows software(9). This is a powerful statistical software most suited for the estimation of qualitative response models. The analysis was done in a number of steps:

Re-coding of raw data: It was necessary to re-code the variables with multiple categories (such as province of residence, area of residence, medical insurance, marital status, education, employment status, race group) into dummy/dichotomous variables taking values of 1 and 0 . We shall demonstrate the recoding process with an example. The respondents province of residence variable (PROVINCE) had nine categories, that is 1=Western Cape, 2=Northern Cape, 3=Eastern Cape, 4=Kwazulu-Natal, 5=Gauteng, 6=Mpumalanga, 7=Northern Province, $8=$ North-West, and $9=$ Free State (OFS). It was recoded into a dichotomous/dummy variable (1-0) as follows:

- from the programmes menu we clicked (using the computer mouse) on Intercooled STATA;

- we clicked on the FILE-OPEN to open the data file;

- we typed in the 'stata commands' window the following commands:

- replace PROVINCE $=1$ if PROVINCE $==2$

- replace $P R O V I N C E=1$ if $P R O V I N C E==5$ replace $P R O V I N C E=0$ if $P R O V I N C E==3$

- replace $P R O V I N C E=0$ if $P R O V I N C E==4$

- replace PROVINCE $=0$ if $P R O V I N C E==6$

- replace $P R O V I N C E=0$ if $P R O V I N C E==7$

- replace PROVINCE $=0$ if $\mathrm{PROVINCE}==8$

- replace $P R O V I N C E=1$ if $P R O V I N C E==9$

The above re-coding process produced a dummy PROVINCE variable with values of: 1 if the respondent lives in either Western Cape, Northern Cape, Gauteng or Free State; and 0 if he/she lives in either Eastern Cape, Kwazulu-Natal, Mpumalanga, Northern Province or North-West. All the other variables with multiple categories were re-coded in a similar manner.

Descriptive analysis: The variables frequency and percentage distributions were obtained using the 'tabulate' command. For example, the values for the PROVINCE variable were obtained by typing in the 'Stata Commands' window: [tabulate PROVINCE] or [tab PROVINCE]. This command was repeated as many times as the number of variables.

The mean and standard deviation values were derived employing the 'summarise' command. All the descriptive statistics were obtained by typing one command as follows: [summarise PROVINCE AREA MEDAID INCOME AGE SEX EDUCATION HSIZE KNOWLEDGE RACE EMPLOYMENT MARITAL STATUS].

Regression analysis: The dependent variable - toilet ownership (TOILET) - was a dummy variable assuming values of: 1 if a respondent had access to a toilet and 0 if not. TOILET was regressed on various socio-economic characteristics of the respondents. Linear probability, logit and probit model 
specifications were fitted on the same data-set for comparative purposes. The coefficients/parameters for the above-mentioned models were estimated by typing the following commands separately in the 'Stata Commands' window:

(a) Linear probability model estimation: [regress TOILET PROVINCE AREA MEDAID INCOME AGE SEX EDUCA TION H SIZE K NOWLEDGE R ACE EMPLOYMENT MARITAL STATUS].

(b) Logistic model estimation: To obtain the "odds ratios" we typed [logistic TOILET PROVINCE AREA MEDAID INCOME AGE SEX EDUCATION HSIZE KNOWLEDGE RACE EMPLOYMENT MARITAL STATUS]. Immediately after deriving the odds ratios, we then typed [Logit] to obtain the co-efficients parameters.

(c) Probit Model Estimation: [probit TOILET PROVINCE AREA MEDAID INCOME AGE SEX EDUCATION HSIZE KNOWLEDGE RACE EMPLOYMENT MARITAL]. As mentioned earlier, all the variables are defined in Table 1.

\section{RESULTS}

Table 2 presents the frequency and percentage distributions. Three hundred five hundred and nineteen $(92.7 \%)$ of the sample said that they had toilets. Two hundred and seventy seven $(7.3 \%)$ said they did not have toilets. Fifty one per cent, $16.8 \%, 1.1 \%, 18.7 \%$, and $5.1 \%$ of the respondents reported to have a flush toilet inside the house, a flush toilet outside the house, a vented improved pit latrine, and a bucket toilet respectively.

\section{Table 1}

Variable descriptions and descriptive statistics

\begin{tabular}{|c|c|}
\hline Variable & $\begin{array}{l}\text { Variable description and descriptive statistics (mean, } \\
\text { standard deviation) }\end{array}$ \\
\hline Toilet & $\begin{array}{l}1=\text { if the he } / \text { she owns a toilet; } 0=\text { otherwise }(\text { mean }=0.927 \text {, } \\
\mathrm{SD}=0.26 \text { ) }\end{array}$ \\
\hline Province & $\begin{array}{l}1=\text { if the respondent lives in Western Cape (WC), } \\
\text { Northern Cape (NC), Gauteng (G), Free State (FS); } \\
0=\text { if the respondent lives in Eastern Cape (EC), Kwazulu } \\
\text { Natal }(\mathrm{KN}) \text {, northwest }(\mathrm{NW}) \text {, Mpumalanga }(\mathrm{M}) \text {, } \\
\text { Northern Province (NP) (mean }=0.393, \mathrm{SD}=0.489)\end{array}$ \\
\hline Area & $\begin{array}{l}\text { Area: } 0=\text { if metro formal area, smaller city/town informal } \\
\text { area, or rural - "homeland"; } 1=\text { if the respondent lives in } \\
\text { metro formal area, metro transitional area, smaller city/ } \\
\text { town formal area, smaller city/town transitional area, or } \\
\text { rural white farms (mean }=0.762, \mathrm{SD}=0.426 \text { ) }\end{array}$ \\
\hline Medaid & $\begin{array}{l}1=\text { if he/she has medical insurance cover; } 0=\text { he/she has } \\
\text { no insurance (mean }=0.300 ; \mathrm{SD}=0.458)\end{array}$ \\
\hline Income & $\begin{array}{l}\text { Total household monthly gross income in Rand } \\
(\text { mean }=1565.734, \mathrm{SD}=2026.163)\end{array}$ \\
\hline Age & Respondents age in years $($ mean $=40.796, \mathrm{SD}=13.586)$ \\
\hline Sex & $1=$ male $; 0=$ female $($ mean $=0.081 ; \mathrm{SD}=0.273)$ \\
\hline Education & $\begin{array}{l}\text { 1=Matriculation and above; } 0=\text { below matriculation } \\
(\text { mean }=0.214, \mathrm{SD}=0.410)\end{array}$ \\
\hline Hsize & $\begin{array}{l}\text { Number of persons living in respondent's household } \\
(\mathrm{mean}=4.810 ; \mathrm{SD}=2.619)\end{array}$ \\
\hline Knowledge & $\begin{array}{l}1=\text { if the respondent thinks that AIDS can be passed on } \\
\text { by having sex with someone who has AIDS without a } \\
\text { condom; } 0=\text { otherwise (mean }=0.291 ; \mathrm{SD}=0.454)\end{array}$ \\
\hline Race & $1=$ if white; $0=$ non-white $($ mean $=0.163, \mathrm{SD}=0.369)$ \\
\hline Employment & $\begin{array}{l}1=\text { if gainfully employed; } 0=\text { if unemployed } \\
(\text { mean }=0.173 ; \mathrm{SD}=0.378)\end{array}$ \\
\hline Marital status & $1=$ if married; $0=$ otherwise $($ mean $=0.498, \mathrm{SD}=0.500)$ \\
\hline
\end{tabular}

Table 2

A comparison of the characteristics of those with and those without toilets

\begin{tabular}{|c|c|c|}
\hline Variable & $\begin{array}{l}\text { Frequency }(\%) \\
\text { for those with } \\
\text { toilets }(n=3519)\end{array}$ & $\begin{array}{l}\text { Frequency }(\%) \\
\text { for those without } \\
\text { toilets }(n=277)\end{array}$ \\
\hline Province: $1 . \mathrm{WC}, \mathrm{NC}, \mathrm{G}, \mathrm{FS}$ & $1339(38.05)$ & $154(55.60)$ \\
\hline 2. EC, KN, NP, M, NW & $2180(61.95)$ & $123(44.40)$ \\
\hline Area: 1. Formal settlements & $2780(79.00)$ & $114(41.16)$ \\
\hline 2. Informal settlements & $739(21.00)$ & $163(58.84)$ \\
\hline \multicolumn{3}{|l|}{ Medaid: 1. Has medical } \\
\hline \multicolumn{3}{|l|}{ 2. Has no medical } \\
\hline Income (in Rands): 0 & $403(11.45)$ & $28(10.11)$ \\
\hline $1-1,000$ & $1,523(43.27)$ & $228(82.31)$ \\
\hline $1,001-2,000$ & $639(18.16)$ & $19(6.86)$ \\
\hline $2,001-3,000$ & $325(9.24)$ & $1(0.36)$ \\
\hline $3,001-4,000$ & $223(6.34)$ & $1(0.36)$ \\
\hline $4,001-5,000$ & $112(3.18)$ & $0(0.00)$ \\
\hline Over 5,000 & $294(8.36)$ & $0(0.00)$ \\
\hline Age: $16-25$ & $448(12.73)$ & $57(20.57)$ \\
\hline $26-35$ & $974(27.67)$ & $79(28.52)$ \\
\hline $36-45$ & $880(25.01)$ & $60(21.67)$ \\
\hline $46-55$ & $603(17.14)$ & $43(15.52)$ \\
\hline 56 and over & $614(17.45)$ & $38(13.72$ \\
\hline \multicolumn{3}{|l|}{ Education: Matriculation } \\
\hline and above & $803(22.82)$ & $268(96.75)$ \\
\hline Below matriculation & $2716(77.18)$ & $9(3.25)$ \\
\hline Hsize: $1-4$ & $1835(52.15)$ & $114(41.15)$ \\
\hline $5-8$ & $1382(39.27)$ & $130(46.93)$ \\
\hline $9-12$ & $257(7.30)$ & $25(9.03)$ \\
\hline $13-16$ & $42(1.19)$ & $7(2.53)$ \\
\hline $17-20$ & $3(0.09)$ & $1(0.36)$ \\
\hline Knowledge: 1 Yes & 3207 (91.13) & $232(83.75)$ \\
\hline 2. No & $312(8.87)$ & $45(16.25)$ \\
\hline Race: 1. African & $1988(56.49)$ & $253(91.34)$ \\
\hline 2. Coloured & $567(16.11)$ & $23(8.30)$ \\
\hline 3. Indian & $346(9.83)$ & $1(0.36)$ \\
\hline 4. White & $618(17.56)$ & $0(0.00)$ \\
\hline Employment: 1 Yes & $545(15.49)$ & $5(1.81)$ \\
\hline 2 No & $2974(84.51)$ & $272(98.19)$ \\
\hline Marital status: 1. Married & $1733(49.25)$ & $156(56.32)$ \\
\hline $\begin{array}{l}\text { 2. Single, widowed } \\
\text { separated, divorce }\end{array}$ & $\begin{array}{l}\text { d, } \\
\text { d } 1786(50.75\end{array}$ & $121(43.68)$ \\
\hline
\end{tabular}

The BLM, BPM and LPM coefficients, $\mathrm{z}$ and $\mathrm{p}$ values are summarised in Tables 3 and 4 . A Chi-square $(\chi 2)$ test was used to determine the overall significance of the model. That is, to test the null hypothesis (Ho) that all the regression coefficients are jointly not significantly different from zero. Since the observed/computed $\chi 2$ of 414.88 in BLM (and 422.10 in both LPM and BPM) was greater than the critical $\chi 2$ (26.76), we rejected the null hypothesis with $99.5 \%$ confidence. Also note that in all the regressions reported in Tables 3 and 4, the likelihood ratios are high and statistically significant, indicating that toilet owners, as a group, can be distinguished from those who do not own toilets on the basis of the explanatory variables included in the two tables. In addition, it is worthwhile noting that the coefficients $\left(\beta_{\mathrm{s}}\right)$ and $\mathrm{p}$-values for the three model specifications are virtually identical. 
Table 3

Estimated logit model, odd ratios, coefficients, $z$ and $p$ values

\begin{tabular}{|c|c|c|c|}
\hline Explanatory variable & Odds ratio (z-value) & Coefficient (z-value) & $\mathrm{P}>/ \mathrm{z} /$ \\
\hline Province & $0.585(-3.438)$ & $-0.537(-3.438)$ & 0.001 \\
\hline Area & $2.430(6.184)$ & $0.888(6.184)$ & 0.000 \\
\hline Medaid & $5.557(4.022)$ & $1.715(4.022)$ & 0.000 \\
\hline Income & $1.001(6.959)$ & $0.001(6.959)$ & 0.000 \\
\hline Age & $1.021(3.934)$ & $0.021(3.934)$ & 0.000 \\
\hline Sex & $2.240(2.088)$ & $0.806(2.088)$ & 0.037 \\
\hline Education & $2.537(2.579)$ & $0.931(2.579)$ & 0.010 \\
\hline Hsize & $0.966(-1.331)$ & $-0.034(-1.331)$ & 0.183 \\
\hline Knowledge & $1.800(3.194)$ & $0.588(3.194)$ & 0.001 \\
\hline Race & $1.580(2.115)$ & $0.457(2.115)$ & 0.034 \\
\hline Employment & $1.546(2.546)$ & $0.436(2.546)$ & 0.011 \\
\hline Marital status & $0.647(-3.146)$ & $-0.436(-3.146)$ & 0.002 \\
\hline Constant & - & $0.544(1.792)$ & 0.073 \\
\hline Number of observations & 3796 & 3796 & - \\
\hline $\mathrm{Chi}^{2}$ (d.f.) & $414.88(12)$ & $414.88(12)$ & - \\
\hline Prob>Chi ${ }^{2}$ & 0 & 0 & - \\
\hline Pseudo $\mathrm{R}^{2}$ & 0.2092 & 0.2092 & - \\
\hline Log likelihood ratios & -784.298 & -784.298 & - \\
\hline
\end{tabular}

Table 4

Estimated probit and linear probability model coefficients, $z$ and $p$ values

\begin{tabular}{|c|c|c|c|}
\hline \multirow[t]{2}{*}{ Explanatory variable } & \multicolumn{2}{|c|}{ Coefficient and z-value in parentheses } & \multirow[t]{2}{*}{$\mathrm{P}>/ \mathrm{Z} /$} \\
\hline & Binary probit model & Linear probability model & \\
\hline Province & $-0.267(-3.228)$ & $-0.267(-3.228)$ & 0.001 \\
\hline Area & $0.504(6.604$ & $0.504(6.604)$ & 0.000 \\
\hline Medaid & $0.772(4.328)$ & $0.772(4.328)$ & 0.000 \\
\hline Income & $0.0005(7.051)$ & $0.0005(7.051)$ & 0.000 \\
\hline Age & $0.011(4.120)$ & $0.011(4.120)$ & 0.000 \\
\hline Sex & $0.379(2.056)$ & $0.806(2.088)$ & 0.040 \\
\hline Education & $0.465(2.723)$ & $0.465(2.723)$ & 0.006 \\
\hline Hsize & $-0.023(-1.705)$ & $-0.023(-1.705)$ & 0.088 \\
\hline Knowledge & $0.320(3.457)$ & $0.319(3.457)$ & 0.001 \\
\hline Race & $0.270(2.410)$ & $0.270(2.410)$ & 0.016 \\
\hline Employment & $0.231(2.580)$ & $0.231(2.580)$ & 0.010 \\
\hline Marital status & $-0.235(-3.225)$ & $-0.235(-3.225)$ & 0.001 \\
\hline Constant & $0.382(2.383)$ & $0.382(2.383)$ & 0.017 \\
\hline Number of observations & 3796 & 3796 & - \\
\hline $\mathrm{Chi}^{2}$ (d.f.) & $422.10(12)$ & $422.10(12)$ & - \\
\hline Prob $>\mathrm{Chi}^{2}$ & 0.0000 & 0.0000 & - \\
\hline Pseudo $\mathrm{R}^{2}$ & 0.2128 & 0.218 & - \\
\hline Log likelihood ratios & -780.689 & -780.689 & - \\
\hline
\end{tabular}

The standardised normal distribution $(Z)$ is used in this study to test whether estimated slope coefficients $\left(\beta_{\mathrm{k}}\right)$ are individually significantly different from zero (i.e. for a one-tailed test). This test dictates that if the computed/ empirical $\mathrm{Z}$-value $\left(\mathrm{Z}_{\mathrm{k}}\right)$ is greater than the critical $\mathrm{Z}$-value $(\mathrm{Zc})$ from a normal distribution table, we should reject the null-hypothesis $(\mathrm{Ho})$ that $\beta=0$; otherwise we should accept the alternative hypothesis that $\beta \neq 0$. For a one-sided $2.5 \%$ test, for example, the critical $\mathrm{Z}$-value is 1.96 . If we observed a computed $\mathrm{Z}$-value higher than 1.96 , we would reject $\mathrm{Ho}(\beta=0)$ at $97.5 \%$ level of confidence, and conclude that $\beta_{\mathrm{k}}$ is significantly different from zero.

In Tables 3 and 4, a positive (negative) sign on an explanatory variable's coefficient indicates that higher values of the variable increase (decrease) the likelihood that a respondent owns a toilet. For example, for the BPM, BLM and LPM regressions, the positive coefficient on the variable INCOME, which is statistically significant, indicates that, other things the same, as households income increases, the likelihood that the respondent owns a toilet also increases.

Seven of the twelve variables in the model (AREA, MEDAID, INCOME, AGE, SEX, EDUCATION, KNOWLEDGE, RACE and EMPLOYMENT) have a statistically significant impact on the likelihood/probability of toilet ownership. In addition, the coefficients for PROVINCE and MARITAL STATUS are both statistically significant, but have a negative sign. 


\section{DISCUSSION}

When interpreting coefficients for the three model specifications, it is important to remember that: in a BLM they represent the impact of a one-unit change in independent variable in question, holding the other explanatory variables constant, on the log of the odds of toilet ownership, not on the probability itself (as is the case with linear probability models) and in a LPM and BPM they represent the impact of a one-unit change in independent variable in question, holding the other explanatory variables constant, on the probability of toilet ownership.

Residential place: There were two variables for the respondents residential place: PROVINCE and AREA. The log of odds that a South African owns a toilet is 0.537 lower if he/she lives in either Eastern Cape, KwazuluNatal, North-West, Mpumalanga, or Northern Province than if he/she lives in either Western Cape, Northern Cape, Gauteng, or Free State, holding the other independent variables constant. The log of odds for a South African living in formal settlements (either metro formal area, metro transitional area, smaller city/town formal area, smaller city/town transition area, or rural white farms) owning a toilet is 0.888 higher than that of their fellow citizens living in informal urban (metro, town and city) settlements and rural areas settled by indigenous Africans. Thus, the people living in affluent provinces, towns and cities suburbs have significantly higher probability of owning or accessing sanitation facilities than those living in deprived provinces and informal urban settlements. The implication for policy is that the scarce public health resources should in future be invested in improving living conditions of the impoverished population groups in the latter provinces and areas.

Demographics: The following demographic factors were included in our analysis: SEX, AGE, MARITAL STATUS, HSIZE and RACE. The male respondents had 0.806 higher $\log$ of odds of owning a toilet than their female counterparts. The disproportionately lower probability of toilet ownership among the females could be attributed to entrenched gender discrimination against women especially in matters relating to education and income-generating activities.

A one year increase in the age of respondents increases the log of the odds that he/she owns a toilet by 0.021 , holding all the other explanatory variables constant. This finding is consistent with the health economics theory that stipulates that as individual's age increases, their stock of health depreciates at an increasing rate, and on average most people would attenuate the rate of depreciation through parsimonious investment in preventive interventions, for example, better personal hygiene practices (10).

The married respondents had 0.436 lower log of odds of owning a toilet than those who were either single, widowed, separated or divorced. The coefficient for household size (HSIZE) was -0.034. This means as respondent's household size increases by one person, the $\log$ of the odds that he/she would be owning a toilet decreases by $3.4 \%$, holding all the other explanatory variables constant. The white respondents have a $45.7 \%$ higher log of odds of owning a toilet than people of colour (Africans, Coloured and Indians). The latter finding could be attributed to the fact that whites in South Africa were favoured by the former apartheid governments socioeconomic policies and human development programmes.

Economics: Our study had two proxies for economic well-being: household income (INCOME) and respondent's employment status (EMPLOYMENT). The estimated slope coefficient for income is positive and highly significant. Thus, the larger the income (INCOME) the greater the $\log$ of odds of owning a toilet. A unit increase in respondent's income leads to a $0.1 \%$ increase in his/her log of odds of owning a toilet. A related finding is that employed (EMPLOYMENT) folks have a $43.6 \%$ higher log of odds of owning a toilet than their unemployed counterparts. These two findings imply there is a close relationship between unemployment, poverty and unequal distributions in income. Todaro(11) argues that those without regular employment or with only scattered parttime employment are usually also among the very poor. We agree with this development economist that one of the major mechanisms for reducing poverty and inequality in less developed nations is the provision of adequately paid, productive employment opportunities for the very poor. In short, the developmental programmes geared at alleviating unemployment and boosting household incomes would most likely lead to an increase in coverage of sanitation facilities. Thus, income-generating-assets re-distribution programmes will most likely have substantial positive public health externality effects, especially for the formerly disenfranchised people of colour.

Know-how: This study had two proxies for knowledge: highest level of secular education attained (EDUCATION) and the level of health education (KNOWLEDGE). The knowledge that AIDS can be contacted by having sexual intercourse with an infected person without using a condom is used in this study as a proxy for health education awareness. The respondents with at least a standard ten (Matriculation) education have 93.1\% higher likelihood of owning toilets than their fellow citizens with a lower education. Those who knew that AIDS can be transmitted by having unprotected sexual intercourse had 58.8\%higher $\log$ of odds of owning a toilet than their less informed counterparts. The above findings suggests that using general and/or health education programmes as a health policy tool ought to improve an individual's efficiency in producing health per unit of health input (including inputs such as hygienic sanitation facilities) utilised. This is consistent with Wagstaff's (12) argument that "one might reasonably suppose that the better educated are in a better position to assimilate information about health matters from the mass-media and their physician than the poorly educated thereby being better equipped to produce a healthy diet from a given outlay of food, to acquaint themselves with the most efficient ways to "prevent 
personal hygiene-related diseases, and to digest information about possible health hazards in their workplace."

If the education component of the Reconstruction and Development Programme is implemented successfully, it will have positive public health spillover effects, such as improvements in levels of toilet coverage in South Africa.

Attitudes to risk: The main outcome of toilet ownership is to reduce the risk of contacting personal hygiene-related diseases. This study has used the possession of health insurance (MEDAID) as a rough indicator of respondent's risk attitudes. The respondents who possessed health insurance cover had $171.5 \%$ higher log of odds of owning a toilet than those interviewees who had no cover. This implies that it is important to put into place policies geared at modifying the risk taking behaviour of those South Africans who manifest both risk-neutrality and risk-loving tendencies (especially with regard to public health matters).

We shall conclude by agreeing with Daily and Ehrlich(5) recommendation that there is need for making massive efforts worldwide, after decades of talk, to provide adequate diets, pathogen-free drinking water and adequate sanitary facilities to everyone. A view shared by the postapartheid South African government. However, while this is jolly good, there are a number questions that beg some answers:

- $\quad$ Given the multitude of equally pressing (if not more important) needs, amidst limited resources and faltering economic growth, who will pay for the universal sanitation (latrine) coverage? One option would be to empower communities (of the haves and have nots) to be able to bear the costs of provision and maintenance of latrines. This question was beyond the scope of the analysis reported in this paper.

- What are the predictors of toilet ownership? In other words, is it possible to isolate the key socio-economic variables correlated with toilet ownership, some of which could be amenable to policy manipulations? This paper has attempted to answer this question. Any government policies geared at improving living conditions (incomes, education, health education, and employment opportunities) for the less-well-to-do in urban and rural areas would increase the probability/ likelihood of toilet ownership in South Africa.

- What are the predictors of toilet use? The latter question is important because it is not enough to assume that necessary behavioural changes would accompany the improved sanitation systems. Thus, there is need for future studies to address this latter issue.

\section{ACKNOWLEDGEMENTS}

J.M.K. is indebted to his mentors Professors Germano M. Mwabu (of the University of Nairobi), Gavin Mooney (of the Universities of Sydney, Tromso and Aberdeen), Anthony J. Culyer, Michael F. Drummond and John Posnett (of the University of York) for the continuing interest in his academic and professional development. The opinions expressed in this paper are ours and should not be attributed to either the WHO, the AHEERA or any of the acknowledged.

\section{REFERENCES}

1. Mckeown, T.et al.An interpretation of the modern rise of population in Europe. Population Studies. 1972; 26:345-382.

2. Mckeown, T.et al. An interpretation of the decline of mortality in England and Wales during the twentieth century. Population Studies. 1972; 29:345-382.

3. World Health Organisation. The international drinking water supply and sanitation decade. Geneva: WHO. 1992: 1-113.

4. Republic of South Africa. Department of Health White Paper for the Transformation of the health system in South Africa. Pretoria: Government Gazette. 1997: 1-232.

5. Daily, G.C. and Ehrlich, P.R. Impacts of development and global change on the epidemiological environment. Environment and Development Economics. 1996; 1:311-345.

6. Community Agency for Social Enquiry (CASE). A National Household Survey of Health Inequalities in South Africa. Washington, D.C.: The Henry J. Kaiser Foundation. 1995.

7. Amemiya, T. Qualitative response models: a survey. J. Economic Literature. 1981; 19:1483-1536.

8. Amemiya, T. Advanced econometrics. Oxford: Basil Blackwell. 1986: 1-350.

9. STATA. Reference Manual (Stata Release 4.0). Texas: Stata Corporation. 1997.

10. Grossman M. On the concept of health capital and the demand for health. J. Political Economy. 1972; 80:223-35.

11. Todaro, M.P.Economics for a developing world.London: Longman. 1977: 1-444.

12. Wagstaff A. The demand for health: theory and applications. J. Epidem. Comm. Hlth. 1986; 40:1 - 11. 